\title{
Elaboração de Carta de Risco de Contaminação por Agrotóxicos para a Bacia do Riacho da Estiva, Brasil
}

\author{
Luciano Cavalcante de Jesus França ${ }^{1 *}$, João Batista Lopes da Silva ${ }^{2}$, \\ Gerson dos Santos Lisboa ${ }^{1}$, Temistocles Pacheco Lima ${ }^{1}$, Fabrina Teixeira Ferraz ${ }^{1}$ \\ ${ }^{1}$ Departamento de Engenharia Florestal, Universidade Federal do Piauí - UFPI, Bom Jesus/PI, Brasil \\ ${ }^{2}$ Departamento de Engenharias, Universidade Federal do Sul da Bahia - UFSB, Teixeira de Freitas/BA, Brasil
}

\begin{abstract}
RESUMO
O objetivo com a realização deste trabalho foi determinar áreas com risco de contaminação por agrotóxicos utilizados na produção de monoculturas anuais na bacia do Riacho da Estiva, afluente do Rio Uruçuí-Preto, Piauí, por meio de álgebra de mapas, fazendo-se uso de planos de informação ambiental para determinar a tendência do comportamento da água, infiltração e escoamento, juntamente com o transporte de agrotóxicos. O cruzamento dessas informações foi utilizado para gerar um mapa com as áreas de risco de contaminação por agroquímicos utilizados. A bacia hidrográfica apresentou elevada antropização, com aumento de aproximadamente 55\% do uso e ocupação do solo por culturas agrícolas em um período de 27 anos (1984 a 2011). Área de $269 \mathrm{Km}^{2}$, que corresponde a $11 \%$ da área da bacia, apresenta alto potencial de risco de contaminação por agroquímicos, $45 \%$ apresentam médio risco de contaminação e $44 \%$ apresentam baixo risco de contaminação.
\end{abstract}

Palavras-chave: sensoriamento remoto, desflorestamento, álgebra de mapas, manejo de bacias hidrográficas.

\section{Latter of Drafting by Pesticide Contamination Risk on the Estiva Stream Watershed, Brazil}

\begin{abstract}
The aims of this work was to determine risk areas with pesticide contamination on the Estiva stream watershed, a tributary of Uruçuí-Preto river, Brazil. Environmental data was used to determine layers of water way, infiltration and runoff with the transport of pesticide. The overlay of this information has generated a map with the risk areas with pesticide contamination. The basin had high human disturbance, with an increase of about $55 \%$ of land use and occupation by agricultural crops, in a period of approximately 27 years (1984-2011). An area of $269 \mathrm{Km}^{2}$, correspondent to $11 \%$ of the basin area, has a high potential pesticide contamination risk, $45 \%$ medium contamination risk and $44 \%$ have little contamination risk.
\end{abstract}

Keywords: remote sensing, defloration, algebra maps, watershed management. 


\section{INTRODUÇÃO}

O modelo atual de desenvolvimento exerce uma pressão cada vez maior sobre os biomas. No cerrado, os recursos naturais vêm sendo intensamente explorados, principalmente pelos setores pecuário e agrícola, que suprem a demanda por alimentos, entretanto põem em risco os recursos naturais e biodiversidade, não somente pelo crescente aumento de áreas cultivadas mas, muitas vezes, pelo manejo inadequado do solo e da vegetação. Diante disso, mostra-se necessária a promoção de programas de conservação e uso sustentável para esse bioma, na óptica de promover políticas públicas e ações de conservação e preservação do que ainda resta da vegetação nativa do cerrado.

Tal situação mantém-se desde o final da década de 1980, no estado do Piauí, com sua crescente participação no cenário do agronegócio brasileiro. Essa região é caracterizada pela exploração com ocupação intensiva de novas áreas abertas para cultivos agrícolas, especialmente para produção da soja. O Piauí possui uma área territorial de $250.934 \mathrm{Km}^{2}$ e cerca de 11,5 milhões de hectares são de cerrado, com uma área de transição de 3,4 milhões de hectares e uma área em torno de 3 milhões de hectares aptos para cultivo. Essas áreas de cerrado localizam-se, geograficamente, em distintos pontos do estado, mas preponderam na região sudoeste e parte do extremo sul piauiense (Reydon \& Monteiro, 2004).

A acelerada exploração para cultivo e produção de culturas anuais nos cerrados vem provocando diversos problemas quanto ao constante uso de agrotóxicos. Esses se caracterizam como úteis à garantia de uma produtividade satisfatória, todavia provocam grandes impactos ao meio ambiente local. Barriuso et al. (1996) situam que a preocupação com esse aumento da utilização de agroquímicos na produção de grãos se deve, principalmente, ao fato de cerca de $20 \%$ dos produtos químicos utilizados poderem alcançar os mananciais por meio do escoamento superficial. No meio ambiente, esses produtos podem agir de duas formas: acumulando-se na biota e contaminando a água e o solo, degradando o meio.

As geotecnologias caracterizam-se como excelentes aliadas em trabalhos de monitoramento florestal e ambiental, sobretudo com aplicabilidade do sensoriamento remoto. Santos et al. (2012) reiteram que as geotecnologias se aplicam a diversos fatores de recursos florestais: delimitação de corredores ecológicos, estudo de ecologia da paisagem, zoneamento ambiental, manejo de bacias hidrográficas, controle de risco de incêndios florestais, do risco de inundação, em monitoramentos e adequações ambientais, em projetos de implementação florestais, planos de manejo de unidades de conservação etc. A potencialidade das geotecnologias adequa-se à avaliação de áreas com intensidade de uso e ocupação do solo e riscos de contaminação por agrotóxicos em áreas de bacias hidrográficas. Caracteriza-se, nas geotecnologias, a composição de linguagens matemáticas, cartográficas e espacial, sendo que a expressão "álgebra de mapas", proposta por Tomlin (1990), refere-se ao conjunto de procedimentos de análise espacial em geoprocessamento que produz novos dados a partir de funções de manipulação aplicadas a um ou mais mapas, ou seja, a análise espacial considerando-se operações matemáticas sobre mapas. Logo, o desmatamento da vegetação nativa, para incorporação de novas áreas para o cultivo da soja e outras monoculturas anuais, e um uso demasiado de agrotóxicos por parte dos produtores, para combate de doenças e pragas, configuram uma realidade preocupante. Nesse sentido, vislumbra-se a necessidade de trabalhos e levantamentos ambientais, com a finalidade de acrescentar e direcionar políticas públicas de conservação, preservação e manejo sustentável dos recursos naturais e do solo desse bioma.

A bacia hidrográfica do Riacho da Estiva, um dos maiores afluentes do Rio Uruçuí-Preto, localizada na região sudoeste do estado do Piauí, vem sofrendo com o processo de abertura de novas áreas para a produção de grãos, bem como com o aumento do uso de defensivos agrícolas para combate às pragas agrícolas, os quais, como consequência, causam muitos danos e impactos ambientais. Essa diminuição dos recursos naturais, principalmente por causas antropogênicas, só acrescenta a preocupação e a busca de estratégias que visem a conservação, restauração e manejo desses recursos, o que auxilia na estabilidade do ecossistema e sustentabilidade do bioma.

Com este trabalho identificaram-se áreas de risco de contaminação por agrotóxicos utilizados na produção de monoculturas anuais na bacia do Riacho Estiva, afluente do rio Uruçuí-Preto, Piauí.

\section{MATERIAL E MÉTODOS}

O Riacho da Estiva é um afluente do rio Uruçuí-Preto, importante rio no sudoeste do Piauí, conhecido por ter águas escuras, decorrentes da alta concentração de 
matéria orgânica e sedimentos, que provocam aumento da turbidez da água. A área de estudo delimitada por este estudo compreende a bacia do Riacho da Estiva, que apresenta área de drenagem total de $3.099 \mathrm{Km}^{2}$, abrangendo cinco municípios: Uruçuí, Sebastião Leal, Manoel Emídio, Palmeira do Piauí e Alvorada do Gurguéia, localizados a oeste do estado do Piauí, conforme apresentado na Figura 1.

Foram utilizados planos de informação ambiental para determinar a tendência do comportamento da água, infiltração e escoamento, juntamente com o transporte de agroquímicos. O cruzamento dessas informações foi utilizado para gerar um mapa com as áreas de risco de contaminação por agroquímicos. A Figura 2 apresenta o fluxograma do cruzamento dos planos de informação utilizados. Todas essas etapas da presente metodologia foram realizadas no software de SIG ArcGIS 10 (ESRI, 2013).

\subsection{Planos de informação}

Para essa etapa fez-se a aquisição de imagens do satélite Landsat (TM) 5, órbita 220 e pontos 65 e 66, no sítio eletrônico do INPE; imagens raster do sensor
Thematic Mapper (TM) (USGS, 2005) contendo as informações de elevação (Modelo Digital de Elevação) foram importadas do sítio eletrônico da USGS (United States Geological Survey); foram levantadas imagens do mapa de solos no sítio eletrônico do IBGE (Instituto Brasileiro de Geografia e Estatística); e dados da quantidade dos agroquímicos utilizados nos últimos anos.

\subsection{Plano de informação: altimetria e declividade do terreno}

A informação altimétrica utilizada originou-se do MDE (Modelo Digital de Elevação) da base SRTM (USGS, 2005), do qual, após a remoção das depressões espúrias, aprofundamento da calha e reconstrução das margens dos rios, obteve-se o MDEHC (Modelo Digital de Elevação Hidrologicamente Consistente). A remoção dessas falhas foi realizada a partir do comando fill, da barra de ferramentas Spatial Analyst, de acordo com técnica utilizada por Ferreira et al. (2010). A declividade da área de estudo foi obtida a partir do MDEHC, sendo agrupadas em três classes: baixa, suave e alta, contendo, respectivamente, declividades menores que $3 \%$ (baixa), entre $3 \%$ e $8 \%$ (suave) e entre $8 \%$ a $20 \%$

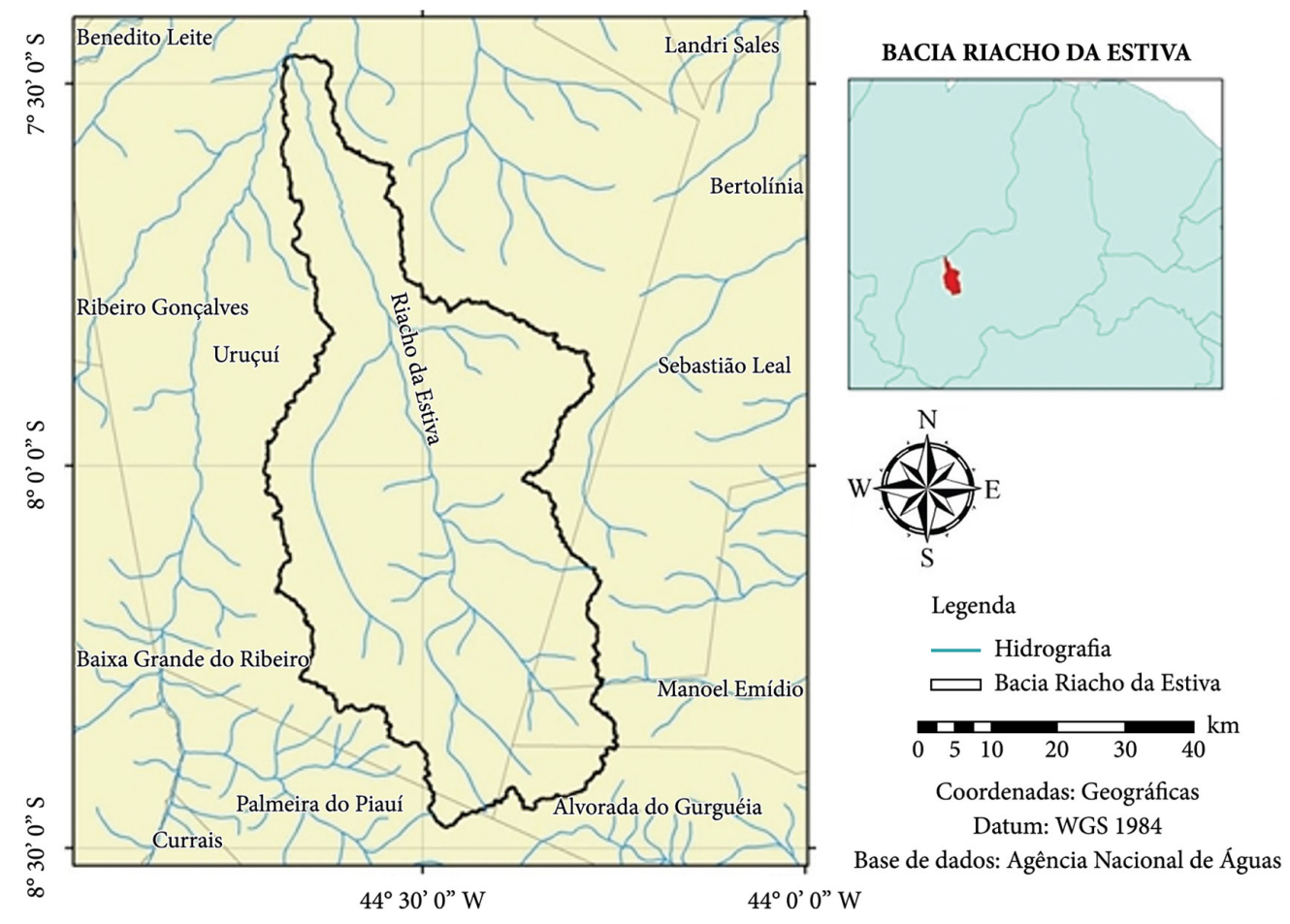

Figura 1. Bacia hidrográfica do Riacho da Estiva, afluente do rio Uruçuí-Preto, Piauí, Brasil. Figure 1. Estiva stream watershed, tributary of Urucuí-Preto river watershed, Piauí, Brazil. 


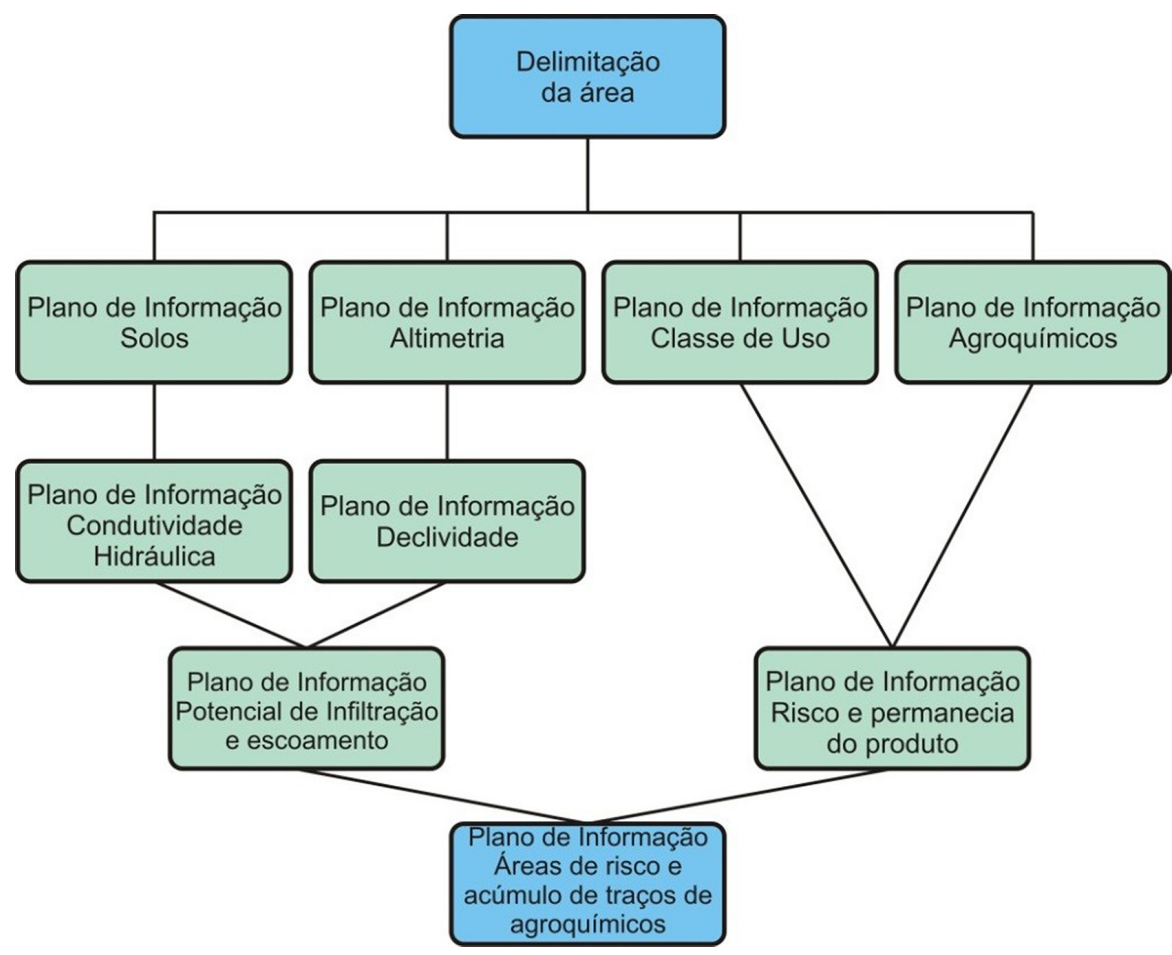

Figura 2. Fluxograma do cruzamento dos planos de informação para a produção da carta de risco. Fonte: Adaptado de Neves et al. (1998).

Figure 2. Environmental data layers for the production of risk charter. Adapted from Neves et al. (1998).

(alta). As áreas com declividade acima de $20 \%$ são de uso restrito para a agricultura.

\subsection{Plano de informação: classe de uso do solo}

O plano de informação da classe de uso e ocupação do solo foi obtido a partir do realce da vegetação com o Índice de Vegetação da Diferença Normalizada (IVDN), a partir das imagens Landsat 5 Sensor TM, bandas 3 e 4, dos anos 1984, 1987, 1999, 1993, 1996, 1999, 2000, 2005, 2008, 2009, 2010 e 2011. As imagens ainda passaram por correções dos efeitos geométricos e radiométricas.

Para realçar a vegetação foi utilizado o Índice de Vegetação da Diferença Normalizada (NDVI), que leva em consideração as correlações existentes entre a reflectância da vegetação e do solo. Nesse caso, quanto maior é a densidade da cobertura florestal, menor será a reflectância na região do visível (vermelho) e maior será a refletância na região do IVP. O NDVI é obtido pela expressão numérica (Equação 1):
$\mathrm{NDVI}=\frac{\mathrm{IVP}-\mathrm{V}}{\mathrm{IVP}+\mathrm{V}}$

em que: IVDN = Índice de Vegetação da Diferença Normalizada; IVP = Região do Infravermelho Próximo (Banda 4); e V = Região do Vermelho (Banda 3).

Após o realce da vegetação pelo NDVI, nas imagens foi aplicada a classificação não supervisionada e elas foram dividida em duas classes: vegetação nativa e áreas antropizadas. Para verificar quais áreas da bacia foram mais exploradas e, consequentemente, apresentavam maiores traços e resíduos de agroquímicos, obteve-se o somatório das imagens NDVI classificadas de todos os anos, para quantificar as áreas mais exploradas ao longo do tempo.

\subsection{Plano de informação: solos}

Para o plano de informação do tipo de solo foi utilizada a classificação do mapa de solos (carta de solos) do sítio eletrônico do IBGE. Para a determinação qualitativa da condutividade hidráulica foram consideradas as 
variáveis textura, estrutura, estabilidade de agregados e profundidade de solo, conforme proposto por Gomes et al. (1996). Com a combinação dessas quatro variáveis obteveram-se três grupos de condutividade hidráulica: alta, média e baixa. O cruzamento dos dois planos de informação, condutividade hidráulica e classes de declividade, deu origem a um terceiro plano de informação denominado potencial de infiltração e escoamento superficial.

\subsection{Plano de informação: agroquímicos}

Fez-se o levantamento de quais produtos foram utilizados na região nos últimos anos. Esses dados foram obtidos com a SEMAR (Secretaria Estadual de Meio Ambiente e Recursos Hídricos) do município de Bom Jesus, PI, em 2013 (Piauí, 2013).

\subsection{Mapa final de risco}

A análise final foi realizada considerando os locais em que ocorreram simultaneamente fatores que agravavam o risco, consequentemente, as áreas que apresentavam maior uso e ocupação do solo por culturas agrícolas, gerando um mapa final indicando as áreas que mereciam maior atenção. $\mathrm{O}$ acúmulo do escoamento superficial indica a maior concentração de traços dos agroquímicos dentro da bacia hidrográfica, conforme demonstrado anteriormente na Figura 2. Todos os mapas elaborados foram trabalhados em tamanho de pixel de $30 \mathrm{~m}$ e o MDE foi reinterpolado para $30 \mathrm{~m}$, para ficar na mesma escala das imagens Landsat.

\section{RESULTADOS E DISCUSSÃO}

\subsection{Indice de Vegetação da Diferença Normalizada (IVDN)}

Os resultados do NDVI a partir das imagens Landsat 5 TM para os anos 1984, 1987, 1999, 1993, 1996, 1999, 2000, 2005, 2008, 2009, 2010 e 2011 demonstraram forte antropização em toda a bacia hidrográfica, principalmente nas áreas de vegetação nativa do bioma cerrado, resultando no aumento das áreas agrícolas, corroborando Reydon \& Monteiro (2004), os quais afirmaram que a ocupação do cerrado piauiense se iniciou nos anos 1980, porém mais com efetiva produtividade apenas na década de 1990, mediante a produção em larga escala, principalmente da soja. Na Tabela 1 são apresentados os valores da evolução das áreas que sofreram antropização e, posteriormente, corroborado, os mapas da Figura 3, comparando os anos de 1984 e 2011, nos quais se observa-se uma significativa mudança do ambiente.

Comparando-se os anos 1984 a 2011, verifica-se rápida expansão das atividades agrícolas e redução da vegetação nativa, evidenciada pelas áreas em vermelho, que caracterizam as fazendas e talhões agrícolas. Ao longo dos anos, as áreas de cerrado na sub-bacia estão passando por um processo de maior intensificação e uso do solo para cultivo agrícola. O mapa com as áreas de alta exploração, entre o período de 1984 a 2011, mostra que houve uso intenso do solo em aproximadamente $269 \mathrm{Km}^{2}$ da área total da sub-bacia (Figura 4), no qual as áreas em verde representam pouca ou nenhuma exploração $\left(1.685 \mathrm{Km}^{2}\right)$, o uso médio do solo é representado pelas áreas em amarelo $\left(1.144 \mathrm{Km}^{2}\right)$ e o uso intenso, pela cor vermelha. Barbosa et al. (2012) enfatizam que o processo de uso e ocupação tem sido intensificado pelo surgimento, a cada dia, de novos projetos agrícolas, os quais levam a um intenso desmatamento de grandes áreas, dentre outros impactos.

\subsection{Classes de declividade do terreno}

Foi possível obter a área de drenagem da sub-bacia do Riacho da Estiva a partir do MDEHC. No entanto, para se chegar ao MDEHC aperfeiçoado foi necessário

Tabela 1. Evolução das áreas de ocupação agrícola e antropização comparando-se 1984 a 2011.

Table 1. Evolution of agricultural areas and Occupation anthropization comparing 1984 to 2011.

\begin{tabular}{|lcc|}
\hline Ano & Vegetação nativa & $\begin{array}{c}\text { Antropização/ } \\
\text { áreas exploradas }\end{array}$ \\
\hline 1984 & $2.761 \mathrm{Km}^{2}$ & $337 \mathrm{Km}^{2}$ \\
1987 & $2.428 \mathrm{Km}^{2}$ & $670 \mathrm{Km}^{2}$ \\
\hline 1990 & $2.345 \mathrm{Km}^{2}$ & $754 \mathrm{Km}^{2}$ \\
\hline 1993 & $2.506 \mathrm{Km}^{2}$ & $593 \mathrm{Km}^{2}$ \\
\hline 1996 & $2.542 \mathrm{Km}^{2}$ & $557 \mathrm{Km}^{2}$ \\
\hline 1999 & $2.539 \mathrm{Km}^{2}$ & $560 \mathrm{Km}^{2}$ \\
\hline 2000 & $2.510 \mathrm{Km}^{2}$ & $589 \mathrm{Km}^{2}$ \\
\hline 2005 & $2.508 \mathrm{Km}^{2}$ & $591 \mathrm{Km}^{2}$ \\
\hline 2008 & $2.473 \mathrm{Km}^{2}$ & $626 \mathrm{Km}^{2}$ \\
\hline 2009 & $2.512 \mathrm{Km}^{2}$ & $587 \mathrm{Km}^{2}$ \\
\hline 2010 & $2.430 \mathrm{Km}^{2}$ & $668 \mathrm{Km}^{2}$ \\
\hline 2011 & $2.321 \mathrm{Km}^{2}$ & $778 \mathrm{Km}^{2}$ \\
\hline
\end{tabular}



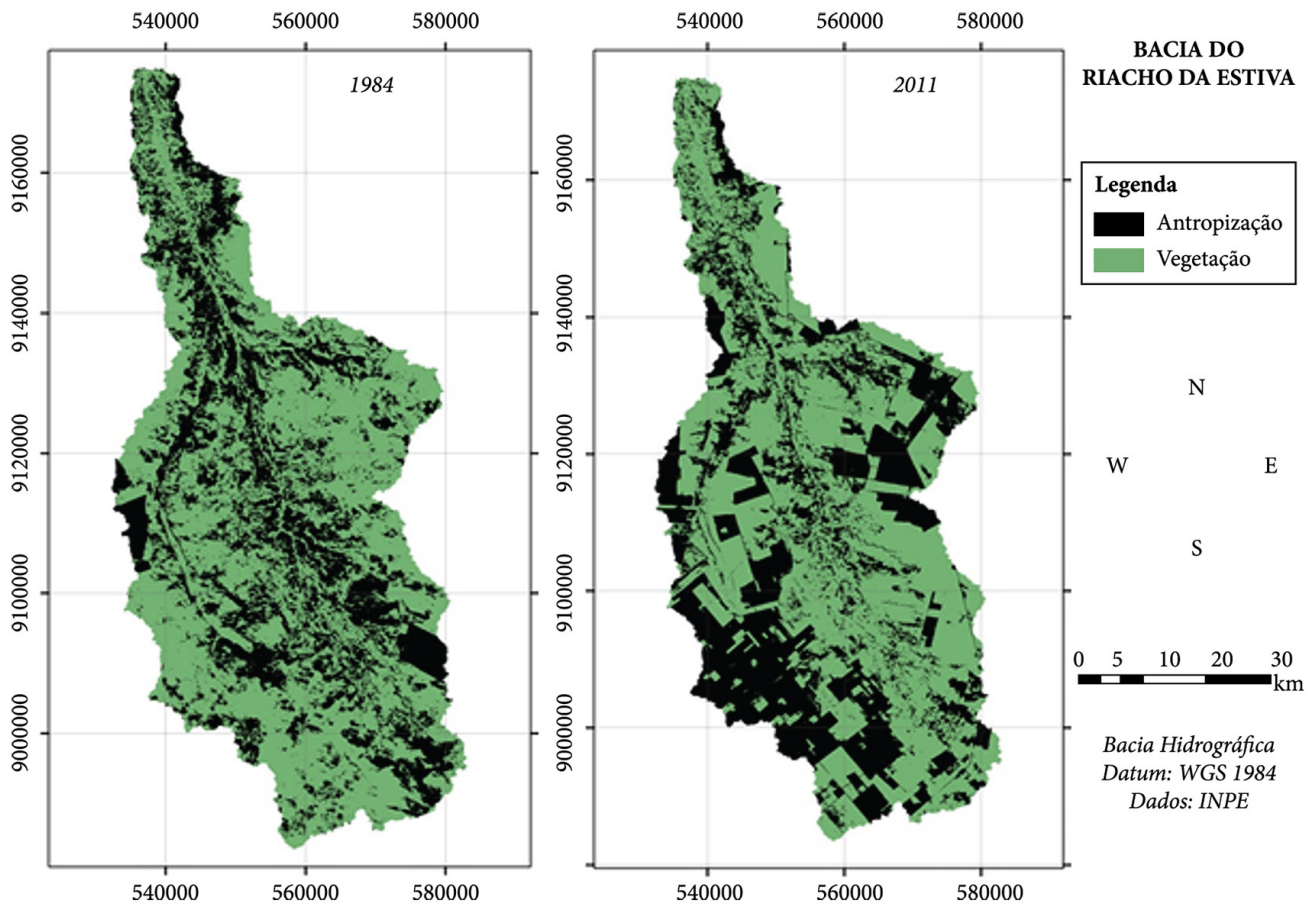

Figura 3. Mapa da antropização entre 1984 e 2011 na sub-bacia do Riacho da Estiva.

Figure 3. Map anthropization from 1984 to 2011 in the sub -basin of the stream of stowage.

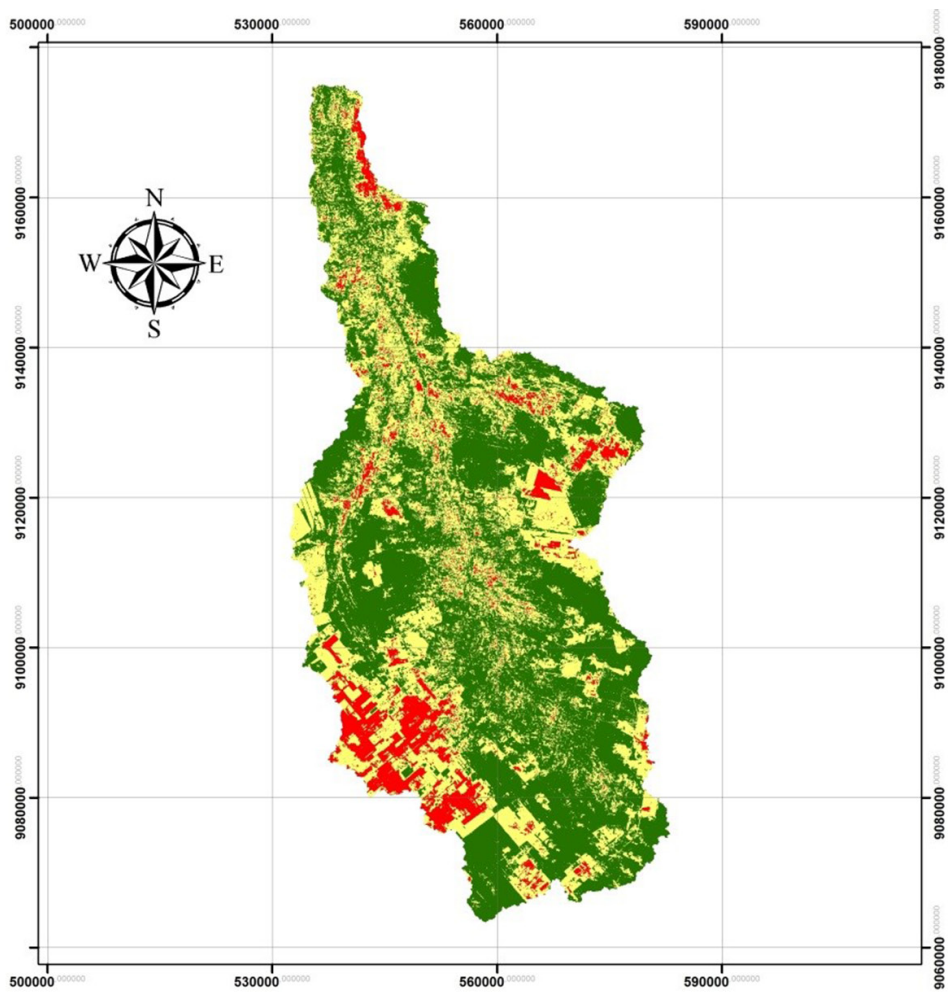

MAPA INTENSIDADE

DE USO DO SOLO

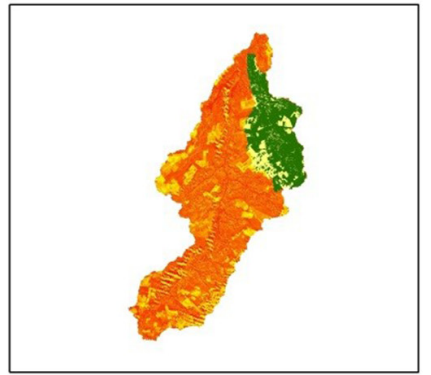

\section{Legenda}
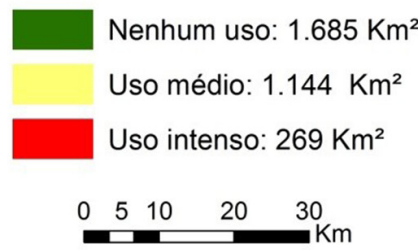

Coordenadas: UTM

Datum: WGS 1984

Base de Dados: ANA e SRTM

Figura 4. Mapa apresentando a intensidade de uso do solo pela exploração agrícola e consequentes características da antropização entre 1984-2011.

Figure 4. Map displays Intensity of land and agricultural crop during 1984-2011. 
remover as depressões espúrias, oriundas de falhas no levantamento dos dados das imagens SRTM, responsáveis por impedir o escoamento superficial progressivo em determinados pontos da bacia. Através do MDEHC foi possível determinar as classes de declividade do terreno por intermédio do MDE, apresentado na Figura 5.

Constatou-se que a maior parte da sub-bacia apresentou baixa declividade, apresentada na cor amarela, declividade inferior a 3\%, característica apropriada para a operação de maquinário e implementos agrícolas utilizados no plantio, colheita de grãos e outras atividades de caráter agrícola, cenário apto a intensa mecanização da produção.

\subsection{Mapa de solos e condutividade hidráulica}

É predominante na bacia hidrográfica a classe de solo Latossolo Amarelo, correspondente às principais áreas de cultivo, seguida de Latossolo Vermelho e uma pequena porção de Neossolos (Figura 6). O conhecimento da tipologia dos solos é um fator de relevância, pelo fato de as propriedades físicas e os atributos do solo serem válidos para a determinação da condutividade hidráulica do solo (Figura 7). Os latossolos predominam no cerrado brasileiro e, segundo Santos et al. (2010), estão presentes em $46 \%$ da área do bioma cerrado, caracterizando-se como solos de baixa fertilidade e alta acidez, sobretudo tratam-se de solos antigos, profundos, com boa drenagem e que se assentam em relevos planos ou levemente ondulados.

Elaborou-se ainda o mapa de condutividade hidráulica, apresentado na Figura 6, a partir das classes de solo. Observa-se que a maior parte da bacia apresenta baixa condutividade hidráulica, o que propicia o acúmulo de água e, consequentemente, a permanência dos traços de agrotóxicos. Observa-se ainda que as áreas com maior condutividade hidráulica trazem informação a respeito das áreas de baixões, conforme apresentado no mapa. São as áreas em azul, que fazem referência aos locais onde são acentuados os declives, locais referentes a áreas não cultivadas. Essas áreas muitas

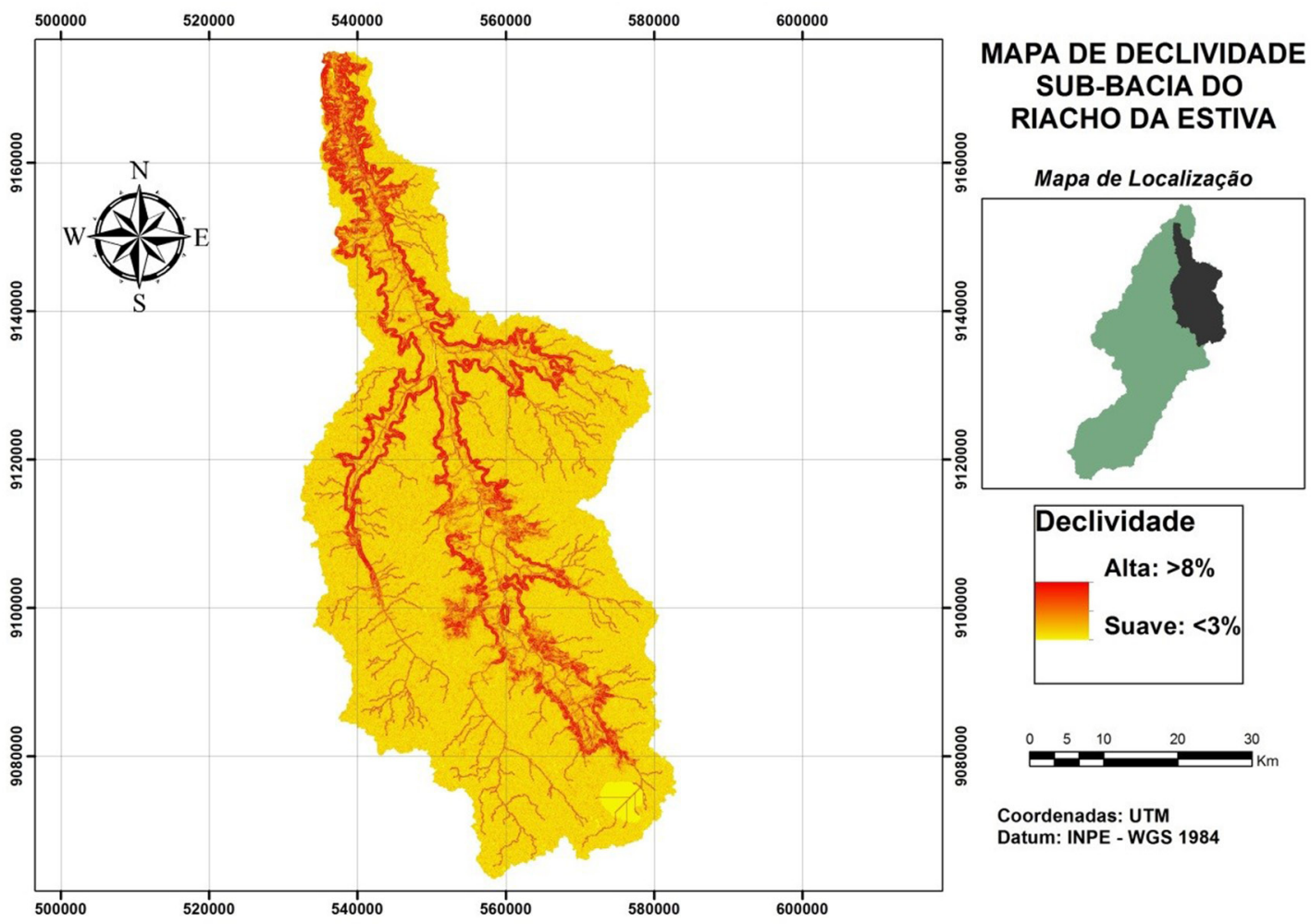

Figura 5. Classes de declividade da sub-bacia do Riacho da Estiva, com baixa declividade em amarelo e alta declividade em vermelho.

Figure 5. Slope classes of sub-basin of Estiva stream watershed, with low slope in yellow and steep slopes in red. 


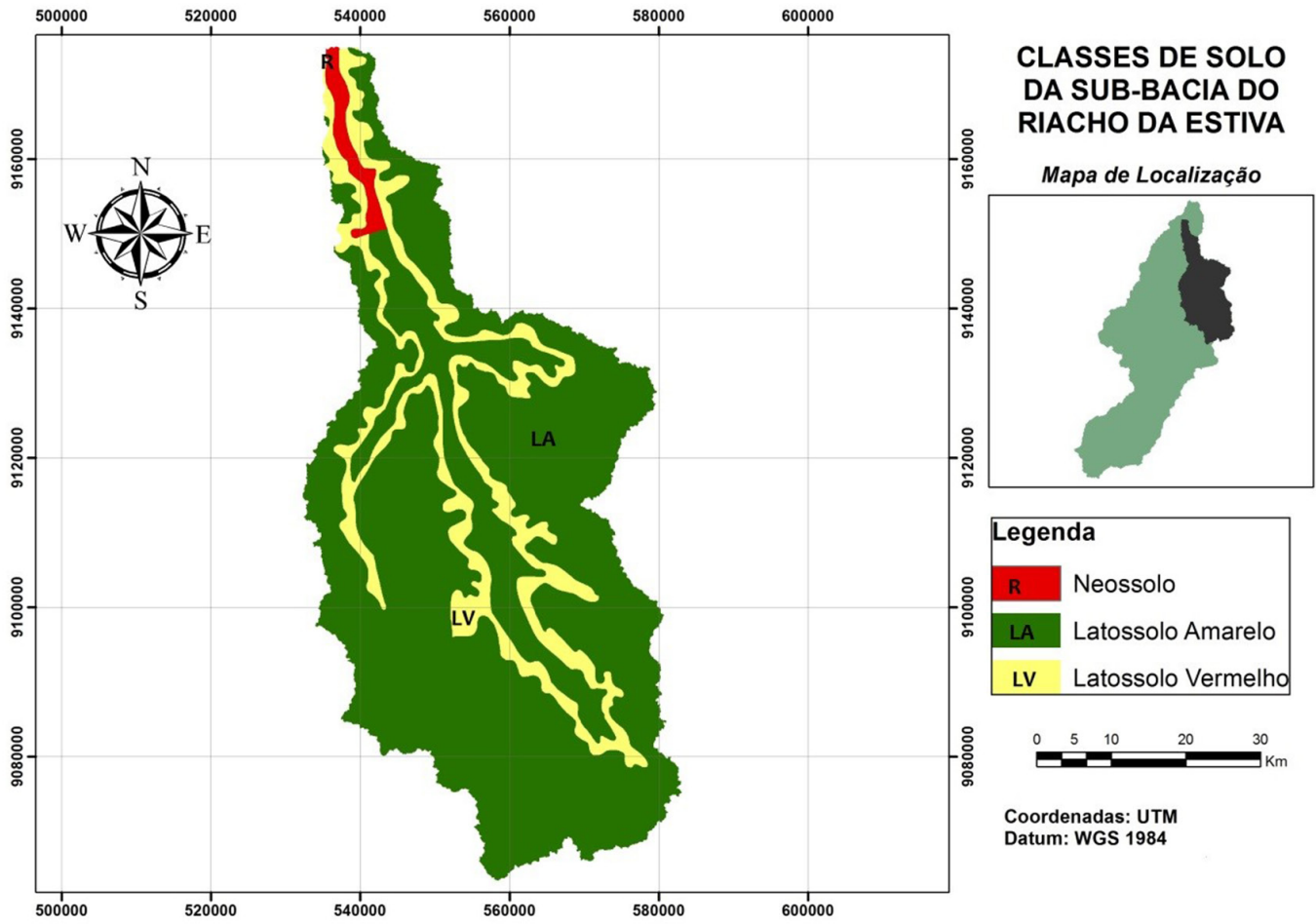

Figura 6. Mapa de classes de solo existentes na sub-bacia do Riacho da Estiva. Figure 6. Soil class map existing on the Estiva stream watershed.

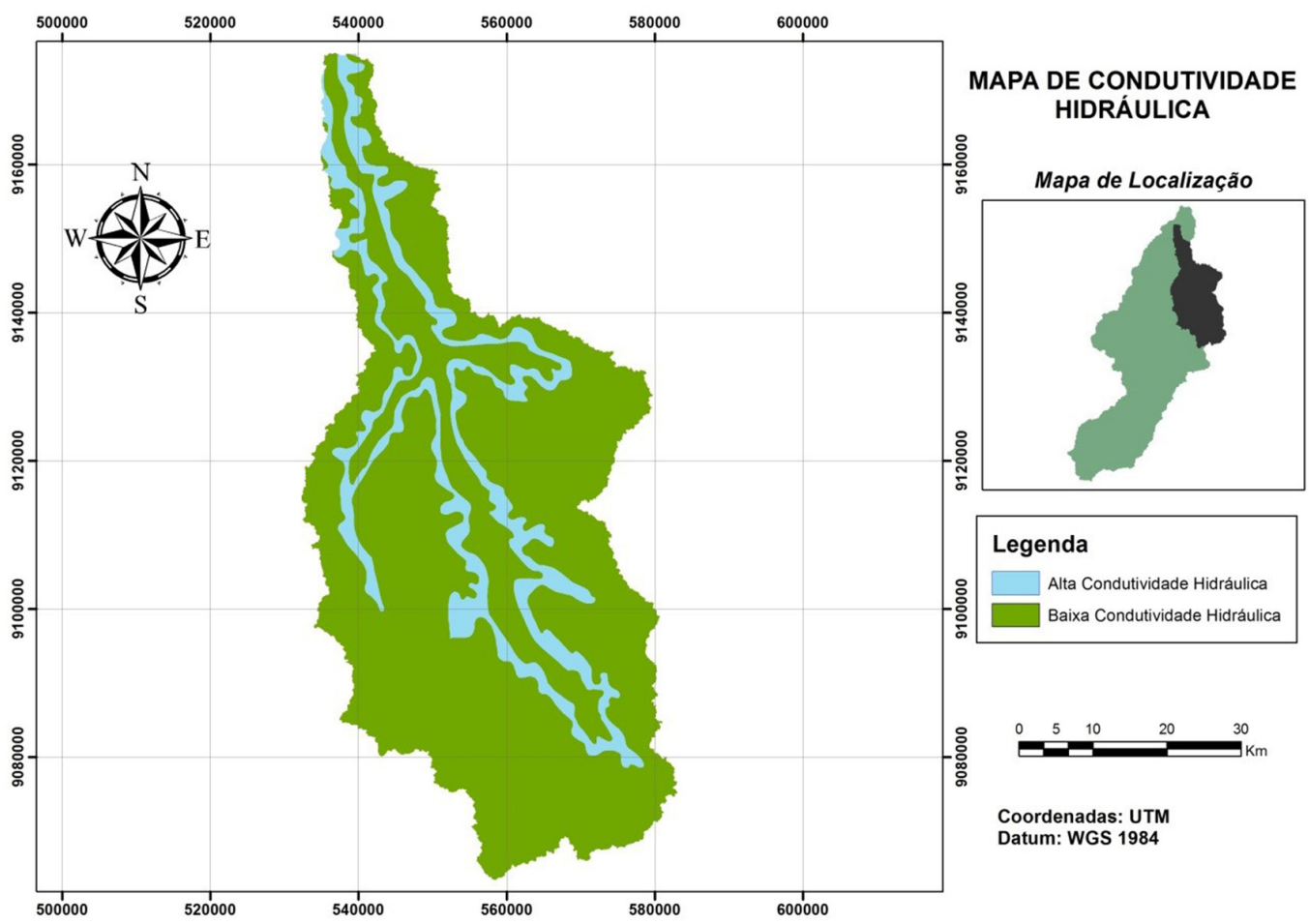

Figura 7. Condutividade hidráulica da sub-bacia do Riacho da Estiva.

Figure 7. Hydraulic conductivity in a sub-basin on the Estiva stream watershed. 
vezes recebem com o escoamento superficial provindo das chuvas muitos sedimentos acompanhados desses traços de agrotóxicos, chegando até as áreas de floresta nativa e as comunidades locais.

\subsection{Mapas do potencial de infiltração e escoamento superficial}

A partir do cruzamento dos planos de informação de declividade do solo (Figura 5) e de condutividade hidráulica (Figura 7), gerou-se o mapa do potencial de infiltração da água e escoamento superficial do solo, apresentado na Figura 8. Nessa figura observam-se diferentes potenciais de infiltração do solo, sendo que os locais que apresentaram alto potencial de infiltração foram os mesmos locais que apresentaram baixa declividade do solo, demonstrando a alta capacidade de infiltração do solo nessas áreas. Nas áreas onde se encontram os grandes projetos agrícolas, os solos apresentaram elevado potencial de infiltração, podendo acarretar a contaminação de águas subterrâneas.

\subsection{Mapa final de risco de contaminação}

Para a obtenção do mapa final de risco de contaminação por agrotóxicos, foi realizado o cruzamento entre os potenciais de infiltração, uso e exploração do solo. As áreas com declividade suave ou levemente onduladas foram as que apresentaram maior concentração de projetos agrícolas, pois são as áreas mais planas e aptas à mecanização, que possivelmente apresentam cultivo de soja e outras monoculturas, acarretando a utilização frequente de agroquímicos. Esses produtos podem percolar ou serem lixiviados no perfil do solo, devido ao alto potencial de infiltração, e, consequentemente, acarretar problemas ambientais com a contaminação do lençol freático. Ribeiro \&Vieira (2010) afirmam que a água é uma das vias primárias pelas quais os agrotóxicos são transportados dos locais em que foram aplicados para outros compartimentos do ciclo hidrológico, e que os contaminantes podem atingir as águas superficiais por meio do escoamento das águas da chuva e da irrigação, ou subterrâneas,

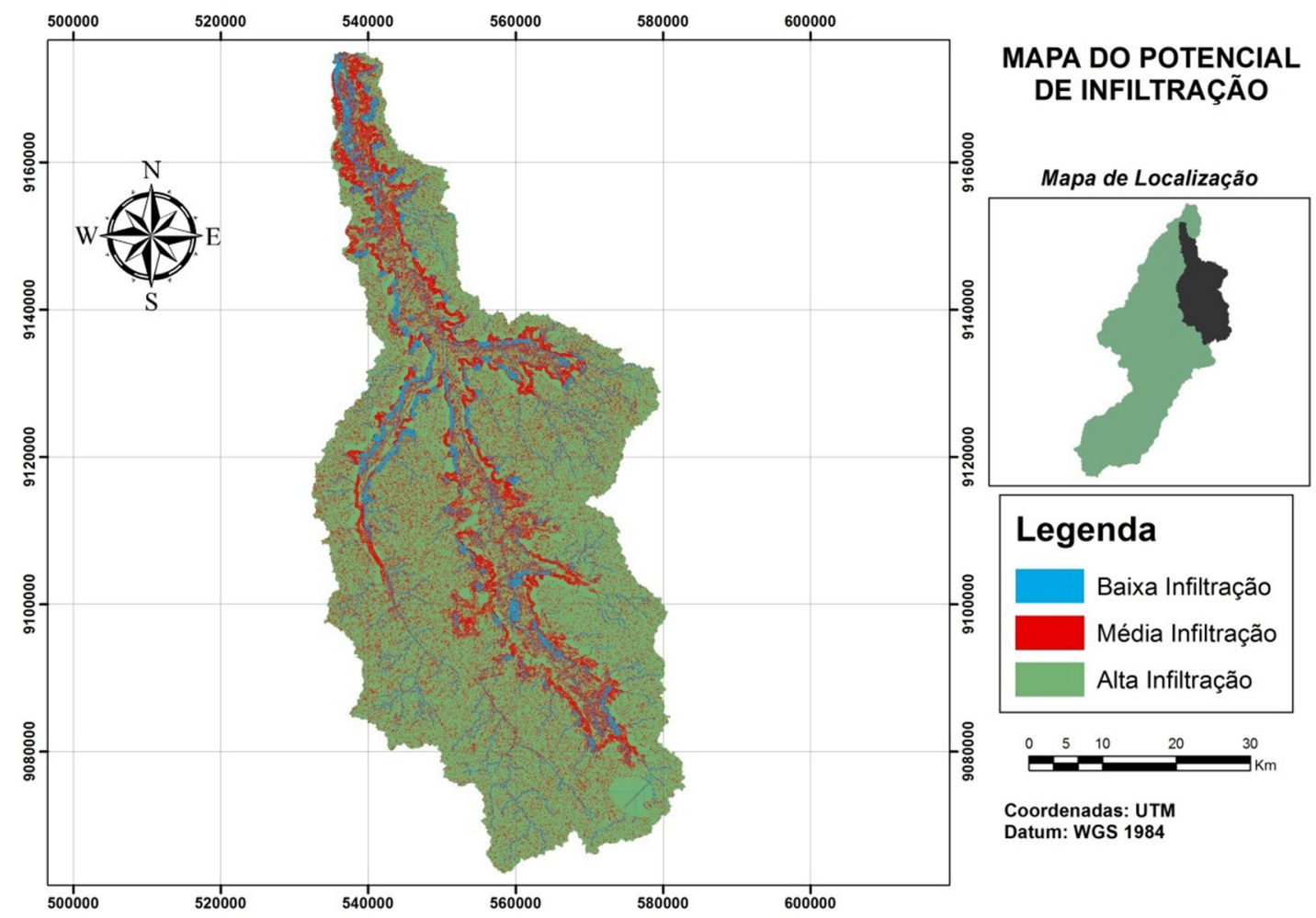

Figura 8. Potencial de infiltração e escoamento superficial na sub-bacia do Riacho da Estiva. Figure 8. Potential infiltration and runoff on the Estiva stream watershed. 
pela drenagem e percolação no solo. Dessa forma, há possibilidade de contaminação de áreas próximas a mananciais superficiais por meio do escoamento superficial, podendo causar problemas ambientais graves decorrentes do uso crescente de agrotóxicos para controle de pragas e doenças, prática comum na agricultura convencional estabelecida na sub-bacia do Riacho da Estiva para assegurar e garantir a produção satisfatória de grãos. Na Figura 9 são apresentados os locais com maior risco de estar contaminados ou propícios a serem contaminadas com a utilização dos agrotóxicos.

Entende-se que além das áreas indicadas como susceptíveis de contaminação ou de estarem contaminadas, caracterizam apenas as áreas de intensa atividade de exploração e uso agrícola, contudo os agrotóxicos ainda assim podem ser lixiviados para os mananciais, uma vez que a problemática ambiental concentram-se em uma grande área de influencia. Na Figura 10 são apresentados graficamente os riscos de contaminação nessa bacia hidrográfica a partir da quantificação das áreas analisadas.
Observa-se que as áreas com alto potencial de risco de contaminação por agrotóxicos cobrem aproximadamente $11 \%$ do total da área em estudo, correspondendo a $269 \mathrm{Km}^{2}$; as áreas com pouco ou médio risco de contaminação representam $44 \%$ do total da área, o que corresponde a $1.144 \mathrm{Km}^{2}$; e as áreas com nenhum risco somam $45 \%$ do total da área, $1.685 \mathrm{Km}^{2}$. Entende-se que grandes áreas com risco de acúmulo e contaminação podem afetar todas as formas de organização vegetal e animal, corroborando Soares \& Porto (2007), os quais destacam que a dispersão de agrotóxicos no ambiente pode causar um desequilíbrio ecológico na interação natural entre duas ou mais espécies, e que alguns agrotóxicos, além de erradicarem as pragas, também eliminam seus inimigos naturais, ou seja, seus predadores e competidores.

Embora não seja possível evidenciar a contaminação das águas superficiais e subsuperficiais, pode-se fornecer a base para definição dos locais com maior potencial de risco de contaminação. Na Tabela 2 encontram-se os dados que levam em consideração as classes toxicológicas dos agroquímicos utilizados.

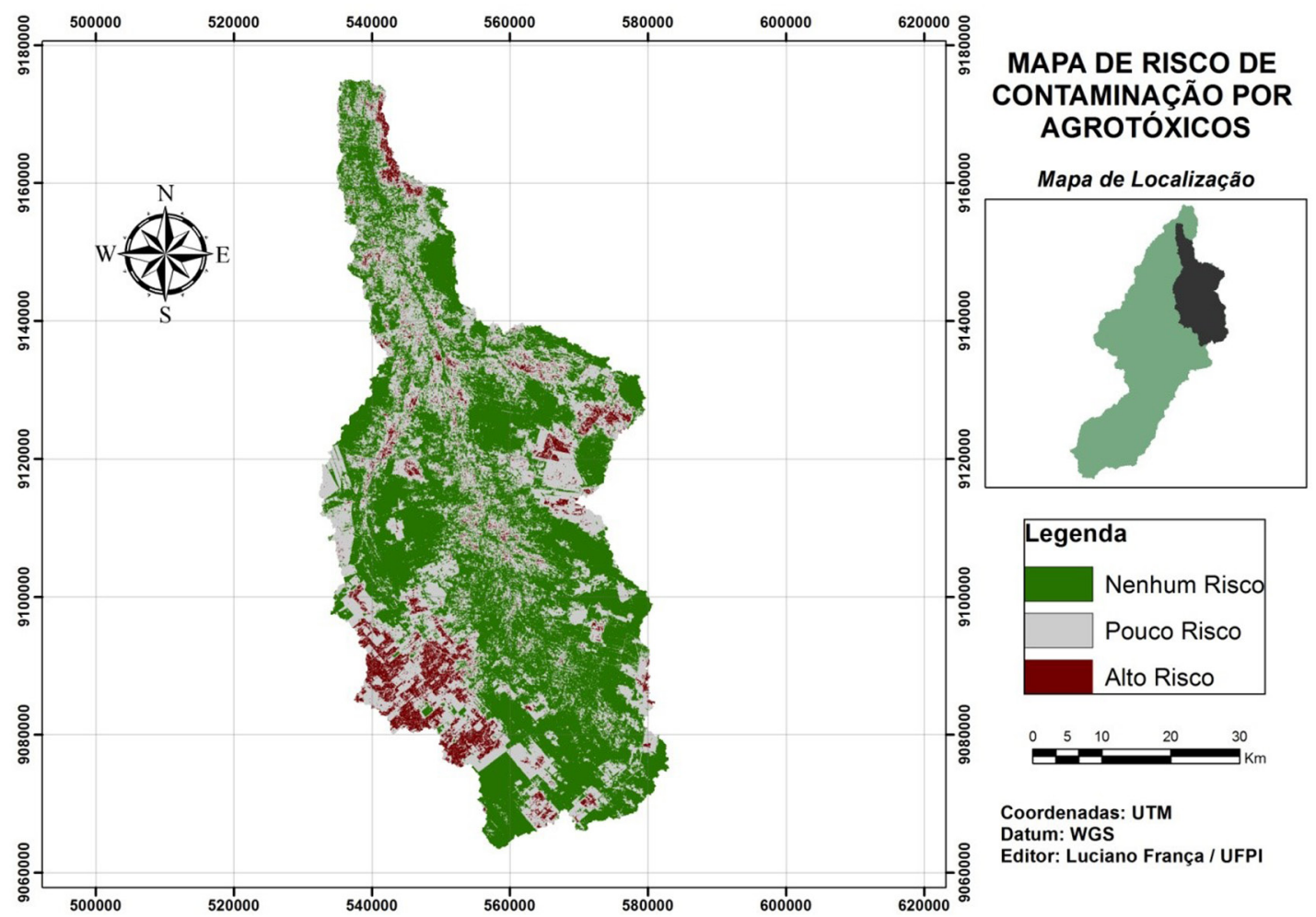

Figura 9. Mapa final de risco de contaminação por agrotóxicos na sub-bacia do Riacho da Estiva. Figure 9. Areas with pesticide contamination risk on the Estiva stream watershed. 
Tabela 2. Porcentagem e número de produtos de todas as classes de toxidez dos agrotóxicos usados na região de sul do Piauí, em quatro anos (Piauí, 2013).

Table 2. Percentage and number of all products toxicity classes of pesticides used in the southern region of Piauí, in four years (Piauí, 2013).

\begin{tabular}{|c|c|c|c|c|c|c|c|c|c|}
\hline & \multicolumn{8}{|c|}{ ANOS } \\
\hline & & \multicolumn{2}{|c|}{2009} & \multicolumn{2}{|c|}{2010} & \multicolumn{2}{|c|}{2011} & \multicolumn{2}{|c|}{2012} \\
\hline & & $\mathbf{N}^{\circ}$ produtos & $(\%)$ & $\overline{N^{\circ} \text { produtos }}$ & $(\%)$ & $\mathbf{N}^{\circ}$ produtos & $(\%)$ & $\overline{\mathbf{N}^{\circ} \text { produtos }}$ & $(\%)$ \\
\hline \multirow{4}{*}{$\begin{array}{c}\text { Classes de } \\
\text { toxidez }\end{array}$} & I & 108 & 22,13 & 102 & 21,16 & 251 & 24,95 & 118 & 21,03 \\
\hline & II & 102 & 20,9 & 124 & 25,73 & 229 & 22,76 & 116 & 20,68 \\
\hline & III & 199 & 40,78 & 154 & 31,95 & 349 & 34,69 & 250 & 44,56 \\
\hline & IV & 79 & 16,19 & 102 & 21,16 & 177 & 17,59 & 77 & 13,73 \\
\hline \multicolumn{2}{|c|}{ TOTAL } & 488 & 100 & 482 & 100 & 1006 & 100 & 561 & 100 \\
\hline
\end{tabular}

Classe I: extremamente tóxico; classe II: altamente tóxico; classe III: moderadamente tóxico; classe IV: pouco tóxico.

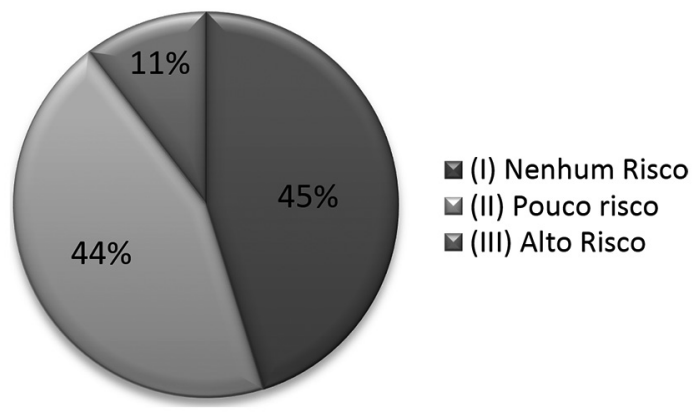

Figura 10. Riscos de contaminação na bacia do Riacho da Estiva.

Figure 10. Pesticide contamination risk on the Estiva stream watershed.

Nota-se que no ano de 2012, em comparação com 2009, houve um aumento no uso de agrotóxicos de classe extremamente tóxica, de classe altamente tóxica e de classe moderadamente tóxica, tendo apenas a classe pouco tóxica suave redução no uso. Isso demonstra considerável aumento em um comparativo de apenas quatro anos, o que requer maior atenção, fiscalização na venda desses produtos e maior preocupação com os possíveis impactos ambientais provocados por esse aumento no uso de agroquímicos no combate a pragas e doenças.

\section{CONCLUSÕES}

Os resultados obtidos nesta pesquisa indicaram que ferramentas de SIG contribuíram para a geração dos mapas e interpretação concreta das suas feições. Na sub-bacia hidrográfica do Riacho da Estiva, com base no uso médio e intenso do solo, ocorreu aumento de cerca de $55 \%$ do uso e ocupação do solo por culturas agrícolas, com consequente avanço do desmatamento das áreas de mata nativa na bacia entre 1984 a 2011. Uma área de $269 \mathrm{Km}^{2}, 11 \%$ da área da bacia, apresenta alto potencial de risco de contaminação por agroquímicos, enquanto $1.144 \mathrm{Km}^{2}$ (44\%) apresentam pouco risco de contaminação e $1.685 \mathrm{Km}^{2}$ (45\%) não apresentam nenhum risco de contaminação por agroquímicos. Esses resultados provêm subsídios fundamentais que auxiliam na elaboração de programas de conservação do cerrado e no manejo adequado das atividades que ocorrem dentro dessa e de outras bacias hidrográficas.

\section{STATUS DA SUBMISSÃO}

Recebido: 10 abr., 2015

Aceito: 10 out., 2015

*AUTOR(ES) PARA CORRESPONDÊNCIA

\section{Luciano Cavalcante de Jesus França}

Departamento de Engenharia Florestal, Universidade Federal do Piauí - UFPI, Rodovia Bom Jesus Viana, Km 01, CEP 64900-000, Bom Jesus, PI, Brasil

e-mail: lucianodejesus10@hotmail.com

\section{REFERÊNCIAS}

Barbosa FMA, Costa JJ, Souza MR. A expansão dos fronts agrícolas e planejamento ambiental e territorial no nordeste brasileiro. eixo temático: geoecologia das paisagens, bacia hidrográficas, planejamento ambiental e territorial. Revista Geonorte 2012; 3(4): 379-389.

Barriuso E, Calvet R, Schiavon M, Soulas G. Les pesticides et les polluants organiques des sols: transformation set dissipation. Étudeet Gestion des Sols 1996; 3(4): 279-296. 
Environmental Systems Research Institute - ESRI. ArcGIS Professional GIS for the desktop, version 10.0. Redlands; 2013. Software.

Ferreira GM, Almeida MM, Silva PAB, Mendonça ASF. Utilização de modelo digital de elevação hidrologicamente consistente na obtenção de caracteristicas morfológicas de bacias hidrográficas. In: Anais do XIX Simpósio Brasileiro de Recursos Hídricos; 2010; Macéio. Porto Alegre: ABRH; 2010.

Gomes MAF, Neves MC, Spadotto CA, Luiz ALB. Mapeamento expedito dos potenciais de infiltração e de escoamento superficial da água parasolos da microbacia do Córrego Espraiado em Ribeirão Preto - SP. In: Anais do $10^{\circ}$ Congresso Lantino-Americano de Ciência do Solo; 1996; Águas de Lindóia. SBCS/Eslaq; 1996.

Neves MC, Gomes MA, Luiz AJB, Spadotto CA. Sistemas de informações geográficas: aplicações na agricultura. In: Assad ED. SIG na avaliação do impacto ambiental por agroquímicos. 2. ed. Brasília: EMBRAPA; 1998. p. 241-250.

Piauí. Secretaria Estadual de Meio Ambiente e Recursos Hídricos - SEMAR. Agrotóxicos utilizados na região Sul do Piauí. Teresina; 2013.
Reydon, P. B., Monteiro, L. S. M. Ocupação do Cerrado Piauiense: um processo de valorização fundiária. 2004.

Ribeiro BHD, Vieira EA. Avaliação do potencial de impactos dos agrotóxicos no meio ambiente. São Paulo: Centro de P\&D de Proteção Ambiental, Instituto Biológico; 2010.

Santos AR, Peluzio JBE, Peluzio TMO, Santos GMADA. Geotecnologias aplicadas aos recursos florestais. Alegre: CAUFES; 2012. 249 p.

Santos MA, Barbieri AF, Carvalho JAM, Machado CJ. O cerrado brasileiro: notas de estudo. Belo Horizonte: UFMG/Cedeplar; 2010.

Soares WL, Porto MF. Atividade agrícola e externalidade ambiental: uma análise a partir do uso de agrotóxicos no cerrado brasileiro. Ciência \& Saúde Coletiva 2007; 12(1): 131143. http://dx.doi.org/10.1590/S1413-81232007000100016. PMid:17680064.

Tomlin D. Geographic information systems and Cartographic Modeling. New York: Prentice Hall; 1990.

United States Geological Survey - USGS. Earth Resources Observation and Science. Seamless data distribution system. USA; 2005 [citado em 2011 janeiro 22]. Disponível em: www.usgs.gov 